\title{
7. Information systems in South Australia: a critical investigation
}

\author{
Paula M. C. Swatman
}

School of Computer and Information Science

University of South Australia

Andy Koronios

School of Computer and Information Science

University of South Australia

\begin{abstract}
This study aims to establish the state of information systems (IS) degree programs and research at Adelaide University, Flinders University and the University of South Australia - the three South Australian universities. It examines the location of IS as an academic discipline, its size and presence and the impact of local contingencies. The study reveals only a small IS presence at Flinders University and a modest IS presence, within commerce, at Adelaide University. The largest IS presence in the state's universities is at the University of South Australia, where the IS group is sited in a School of Computer and Information Science (CIS), located within a Division of Information Technology, Engineering and the Environment. The study concludes that although IS in South Australian universities meets some of the criteria for recognition as a mature discipline, the state's unique qualities have played a large part in the unusually low level of academic interest in IS.
\end{abstract}

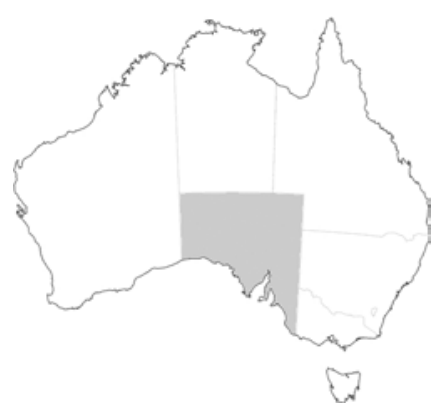

Figure 7.1 Location of South Australia within Australia 


\section{Purpose of the South Australian study}

South Australia is the fourth-largest of the Australian states, with a population of 1.7 million; and it is central to Australia, being the only state to share a border with all other mainland Australian states. It is often referred to as the driest state in the driest inhabited continent of the world. Instead of the convict past common to most of the Australian states, South Australia was settled freely as a British province and proclaimed officially in 1836. It also has a strong German heritage resulting from several decades of German migration in the early to mid-1800s, which has left a unique architectural and phonetic legacy. The capital is Adelaide, with a population of 1.2 million people.

The South Australian study aims to establish the state of IS degree programs and research in its three universities. It examines the location of IS as an academic discipline, its size and presence, the impact of local contingencies, and contributes to the debate about IS as a separate field.

The chapter begins with a discussion of the theoretical framework used to analyse IS research and teaching activities in South Australia, then provides an overview of the three South Australian universities and their teaching activities in the IS field. The chapter then discusses the aspects of IS relevant to this group of case studies - with a particular focus on the University of South Australia, as data were not obtainable from the other two universities on many of these topics.

\section{Research approach}

\section{Theoretical framework guiding the study}

Ridley's (2006) theoretical framework has been developed through a thematic study of IS and non-IS literature. Common components were identified and included in the framework, which was influenced by Whitley's (1984) theory of the establishment of scientific fields. Essentially, Whitley proposed three conditions necessary for the formation of a new field:

1. mechanisms of control such as publication records and an ability to gain research funding

2. research skills and standards

3. a unique symbol set.

Ridley (2006) suggests that Whitley's second and third conditions together comprise 'a core body of knowledge', and adds theory and an agreed set of topics as additional essential components. On this basis, she then constructs a two-tiered framework comprising mechanisms of control, a core body of knowledge, the impact of local contingencies and the degree of professionalism as the first level. The second level builds on the core body of knowledge drawn from Whitley and consists of research and teaching methods and standards, a unique symbol set, key research and teaching IS topics and laws, rules and evidenced guidelines. 
Table 7.1 provides an abridged version of Ridley's own summary of this framework.

Table 7.1 Discipline nature and development framework (adapted from Ridley 2006)

\begin{tabular}{l|l}
\hline Level 1 component & Level 2 component \\
\hline Mechanisms of control & \\
\hline Core body of knowledge & \\
\hline & Research and teaching methods and standards \\
\hline & Unique symbol set \\
\hline & Key research and teaching IS topics \\
\hline Impact of local & Laws, rules and evidenced guidelines \\
\hline contingencies & \\
\hline Degree of professionalism & \\
\hline
\end{tabular}

Ridley (2006) believes this framework is sufficiently robust to accommodate future developments in IS and has tested it (successfully) against the inclusion of pragmatism into the IS literature. This characterisation framework forms the basis for the present chapter.

\section{Data analysis}

This study of IS in South Australia takes the form of a positivist case study (Yin 2003), based predominantly on interviews conducted with IS teaching staff at the University of South Australia and the University of Adelaide, ${ }^{1}$ and enhanced by data drawn from internal and external sources. Case studies of this type frequently make use of a detailed case-study protocol; Australasian study team members developed such a protocol at the time of the original Australasian Journal of Information Systems (AJIS) special issue paper preparation to ensure consistency of data collection across the universities studied. Major objectives of this protocol were to facilitate:

1. comparability across the states

2. consistency across the individual state case studies

3. efficiency in the data-gathering process.

Data were collected by a combination of personal interviews and e-mail questionnaires, filled in by staff and returned to the authors for analysis and review. Existing documentary and archival material was also gathered to supplement the interview data and to provide some triangulation of observations.

Data gathered from interviews and questionnaires were then analysed using the Ridley framework, so that qualitative data collected from participants and

\footnotetext{
${ }^{1}$ A description of Flinders University is included in this chapter for the sake of completeness but, since IS does not exist as a school, department or even a discipline within a school at Flinders University, detailed data were not gathered from Flinders for this study.
} 
quantitative data collated from other sources could be integrated more effectively (Dixon-Woods et al. 2005; Ridley 2006).

The discussion that follows was 'weighted towards themes that appear to have a high level of explanatory value', rather than reflecting how frequently the themes were reported (Dixon-Woods et al. 2005:47).

\section{The universities in this study}

\section{The University of South Australia}

The University of South Australia (UniSA), the largest university in South Australia, was founded on 1 January 1991 through the amalgamation of the South Australian Institute of Technology and the Magill, Salisbury and Underdale campuses of the South Australian College of Advanced Education. It is one of the five Australian Technology Network (ATN) universities (http://www.atn.edu.au/), which have a focus on applied research and whose aim is to develop strategic partnerships between the academic and business sectors. Since its inception, UniSA has quickly earned a reputation as a national leader in collaborative research, it has been recognised nationally for innovation in teaching and it has South Australia's largest intake of international students (and one of the largest in the country). The UniSA has an overall student population of about 33000 and employs more than 3000 staff. It offers almost 400 degree programs from diploma to postgraduate level across four divisions: Health Sciences; Education, Arts and Social Sciences; Information Technology, Engineering and the Environment; and Business.

\section{The University of Adelaide}

Adelaide's first and oldest university was established in 1874 and has approximately 20000 students and 2500 staff. The University of Adelaide has something of a history of firsts, being the first Australian university to admit women to academic courses, in 1881, and the first Australian university to award degrees in science. Today the University of Adelaide, which is a member of the Group of Eight (Go8) universities (see http:/www.go8.edu.au/) - eight of Australia's oldest and most research-intensive universities - extends across four campuses and accommodates more than 4500 international students. It has produced 100 Rhodes Scholars and has five faculties: Engineering, Computer and Mathematical Sciences; Health Sciences; Humanities and Social Sciences; Professions; and Sciences.

\section{Flinders University of South Australia}

Established in 1966 in the southern Adelaide suburb of Bedford Park, Flinders University has approximately 15000 students and 1500 staff. The university takes its name from British explorer Matthew Flinders, who surveyed the South 
Australian coastline in 1802. An early initiative was the decision to build the Flinders Medical Centre on land adjoining the campus and to house the university's medical school, which opened in 1976, within this new public hospital - the first such integration in Australia. When higher education was restructured in South Australia in 1991, Flinders merged with the neighbouring Sturt campus of the former South Australian College of Advanced Education. Flinders University comprises four faculties: Education, Law, Humanities and Theology; Health Sciences; Social Sciences; and Science and Engineering.

Flinders University does offer a Bachelor of Information Technology degree, which has definite similarities with UniSA's Bachelor of Information Technology program, but since both these degrees focus primarily on information technology (IT) rather than IS (offering a 'half-way house' between computer science and IS), this material has not been included in the present, IS-focused study. Flinders also offers a Bachelor of Arts (Geographical Information Systems, GIS) program, offering students enrolled in an arts degree the opportunity to include a major sequence in the area of GIS. This might well be seen as an attraction for students considering an IS degree, but is a rather more specialised offering and, again, is not included in the present chapter.

\section{Size and presence of IS in South Australian universities}

It proved surprisingly difficult to obtain accurate figures for IS student numbers at the three universities - largely because statistics were not available for IS in isolation and therefore had to be extrapolated from combined computing or commerce student numbers. Table 7.2 summarises the 'best guess' numbers provided by each of the universities. For this reason, numbers in this study are reported as 'students', rather than effective full-time student load (EFTSL).

Table 7.2 Numbers of IS staff and students in South Australian universities

\begin{tabular}{l|l|l}
\hline University & No. of IS academics & No. of IS students \\
\hline University of South Australia & 12 & $>1500$ \\
\hline Flinders University & Not available & Not available \\
\hline University of Adelaide & 3 & $>500$ \\
\hline
\end{tabular}

\section{IS at the University of South Australia}

At the time the UniSA was founded, some members of antecedent organisations decided to form a School of Information Systems within the new Business Division. Some of these staff members came from the Institute of Technology, while others had previously been a part of the South Australian College of Advanced Education. One study participant commented:

We had all been in Business Schools teaching IS topics. We believed it worthwhile to have an IS concentration and develop the area academically as it was useful for the uni and the citizens of SA. At the time IS had quite a high profile. I was a founding member along with approx 21-23 
others. We were the first and only School of Information Systems in SA. Flinders University had nothing in the way of IS and Adelaide University had one subject in Computing Science. We developed a range of undergraduate programs which [was] very well received.'

In 1996, the university reduced funding to the school, which resulted in staff cuts and redundancies. In 1996, there were cuts across the Business Division, and IS staff were advised that the annual budget had been reduced from $\$ 2.8$ million to $\$ 1.8$ million. The group had significant financial problems at the time, although it had developed a successful industry placement program with about 40 industry partners and earned a very positive reputation for its engagement with industry. At least one respondent (now retired) believes the group had a mixed relationship with the Division of Business from its inception, claiming there were several attempts to move the discipline out of the Business Division. In that year, the IS discipline group was moved into an accounting and IS school, which also included a group of staff from the administrative management area, which had originally taught secretarial studies and was slowly evolving towards a new focus on the management of corporate administrative functions.

In 2004, a review of the Division of Business resulted in the restructuring of all the schools within that division. This review, combined with a strategic university-wide decision to combine all computing-related disciplines into one school, led to the IS discipline as a whole being transferred to the School of CIS, located within the Division of Information Technology, Engineering and the Environment, which had existed for the life of the university and was already a very much larger school. This merger has resulted in a large and vibrant computing school, based on two campuses (and with teaching offerings on four campuses), with a wide variety of programs covering the full range from computer science through software engineering and IT to IS.

Although some respondents believe that the IS group is smaller and less visible as a result of this merger, it now has three full-time IS professors and one associate professor - in addition to two European adjunct professors who are also IS focused. The combined School of CIS launched a Bachelor of Information Systems for the first time in the history of the university after the merger, and all degree programs offered by the school were reviewed and completely revamped, with significant changes taking place in all degree offerings.

The merger also allowed the UniSA to rationalise the location of the IS staff. Before the move to CIS, the majority of the IS discipline staff ( 12 academics) were based in the School of Accounting and Information Systems at the City West campus, which comprised three discipline areas: accounting, IS and administrative management. Some of the IS courses (those with an 'INFS' prefix) were taught by administrative management staff, while some of the administrative 
management courses were taught by IS staff. These blurred lines of control had simply evolved over time, but were rationalised at the time of the merger.

During the merger discussions, 11 of the 12 IS academic staff agreed to move to the new school and one of the former administrative management staff joined the group moving to CIS. Before the merger, some five IS academics were located in the 'old' CIS at the Mawson Lakes campus in the north of Adelaide, and their courses became part of the revised degrees offered by the enlarged, combined school.

The majority of the IS teaching takes place at the City West campus of the UniSA, where most of the IS staff are still located, with some (predominantly graduate) IS courses also being offered at Mawson Lakes. A number of the largest IS courses are also offered face to face at the Whyalla and Mt Gambier campuses, as well as being taught offshore as part of the transnational degrees being offered in Hong Kong and Malaysia.

The school has an industry advisory group, which has been very supportive of IS programs and has an excellent reputation with local business and with the public sector.

\section{IS student and subject numbers at the University of South Australia}

There is one major similarity between IS at the Universities of South Australia and Adelaide: both universities (as is common around Australia) offer a major, first-year subject to students enrolled in a business or commerce degree. In the case of the UniSA, this subject has an average annual enrolment of approximately 2000-2500 students and is taught over nine separate delivery channels (on-campus/off-campus in Adelaide; through Open University Australia; on-campus in Whyalla and Mt Gambier; as a service teaching offering through the business colleges of the South Australia Institute of Business and Technology [SAIBT] and EBIT; and on-campus in Hong Kong and Malaysia). Running a subject of this size through so many varying delivery methods is a major logistical exercise and involves two academic staff members. A senior member of teaching staff oversees the subject and provides the face-to-face and video-taped lectures, while a more junior member of staff is occupied full time as course manager, coordinating the tutors and off-site lecturers, tutorial material and coordinating/overseeing student contact activities.

Since many of the students enrolled in this subject are taking an accounting degree, the syllabus is influenced strongly by the requirements of the CPA, which accredits the Bachelor of Commerce degree. Nonetheless, this subject is designed and taught by full-time IS academics, who ensure that it provides a thorough grounding in IS for all business students. 
Table 7.3 Course-work offerings within the School of CIS

\begin{tabular}{l|l|l}
\hline Undergraduate courses offered & Postgraduate courses offered & $\begin{array}{l}\text { No. of students enrolled in IS } \\
\text { subjects }\end{array}$ \\
\hline DBBI, DBEB, DBIN, DBIT, DBMS & $\begin{array}{l}\text { DCMI, DGEC, DGMI, DMEC, DMIS, } \\
\text { DMMI, LMCT }\end{array}$ & 1500 approx. \\
\hline
\end{tabular}

The bachelor degrees identified in Table 7.3 are all IS focused-DBIN is a complete Bachelor of Information Systems degree, while the other three are business degrees with an IS focus. The postgraduate offerings vary from being entirely IS focused (for example, DMMI) to having a major IS focus.

\section{IS at the University of Adelaide}

Information systems is located within the School of Commerce at the University of Adelaide and is considered a separate discipline with its own head. With a staff of only three (including the discipline head), IS is focused largely on the core foundation course for the accounting and business IT degrees. We were unable to interview the head of the discipline, and one of the staff members had arrived in South Australia only for the start of the first 2007 semester. The other staff member has been teaching IS for the past three and a half years and was a PhD student at the University of Adelaide before that appointment.

The IS subject is accredited by the CPA as a core component of the commerce degree and therefore has a large undergraduate enrolment (more than 500 students). At postgraduate level, IS is offered in the form of a number of elective subjects, with a current overall enrolment of about 250, including five Masters students and one PhD student. The university does not offer any degree majoring in IS and IS is regarded as a supporting area to other disciplines.

Interestingly, there was a 30 per cent growth in IS numbers in the first semester of 2007, which staff attributed to a combination of the recent lowering of the Tertiary Entrance Requirement (TER) and the university's status as a member of the Group of Eight. In addition, this growth reflects the increase in international students, particularly from China, studying IS.

Information systems at the University of Adelaide is of marginal status, reflected in the comparatively small number of staff and the lack of any IS degrees at either undergraduate or graduate levels. Although there is a compulsory IS subject for some degrees within the School of Commerce (generally for accounting students), its visibility as a discipline or field appears to be in decline at the University of Adelaide. Those teaching IS are strongly business oriented and are convinced of its supportive role within the school-and are not connected to the wider IS community, with the result that they are unaware of the discipline's struggle for survival in other universities. Unfortunately, no information could be gathered relating to the history of IS at this university so it is unclear whether IS has played a more important role in the past. 
The final section of this chapter focuses on influences and issues specific to IS within South Australia. Much of this material relates to activities at the UniSA, because IS at the University of Adelaide is predominantly service teaching for the accounting students and is therefore driven by the needs of the accounting profession and its accreditation practices.

\section{Issues for IS within South Australia}

\section{Characteristics of IS in the state}

South Australia has very few corporate head offices; instead, it has a number of very innovative and successful smaller businesses working in the ICT sector. Even EDS, which had a sizeable representation in Adelaide under the former government (having won a contract to handle all government ICT outsourcing), has now 'right-shored' its South Australian operations to a significant extent, after the current state government's change of its outsourcing policy to one in which government ICT activities are outsourced predominantly to interstate and offshore companies. The lack of a single minister responsible for ICT activities in the state (South Australia has six ministers who share the various aspects of the ICT field) has also helped to create an unusual profile for IS in the state - with many IS activities focused on the activities of imaginative and innovative small companies in such areas as computer gaming, defence or consultancy.

The major ICT group within South Australia is, of course, the defence industry. The decision to build 'smart ships' (air warfare destroyers) in Adelaide has bolstered the existing activities of many high-tech defence companies, which had been working with ASC (formerly the Australian Submarine Corporation) on the development of the Collins-class submarines.

\section{The impact of local contingencies on IS education}

Although the curriculum is naturally affected by industry requirements, IS academics also endeavour to provide industry leadership, rather than simply responding to industry demand.

Local demand does affect IT and IS teaching structure within the state, particularly in terms of content, because students must have certain skills to be employed by local and interstate businesses. It is, however, probably no more affected by industry than other applied disciplines, such as tourism or oenology.

The UniSA has made significant structural changes that affect the teaching of IS - specifically, the move of the IS group from the School of Accounting and Information Systems within the Division of Business, to the School of Computer and Information Science within the Division of Information Technology, Engineering and the Environment. This has enabled the development of a Bachelor of Information Systems degree (IS was formerly offered only as one alternative within the Bachelor of Business degree). As it is the only university 
in South Australia offering IS degrees, there is little (if any) political pressure on the school to provide any particular offerings, although the BBIS/MBIS program (a funded joint program with industry, which takes high performers and fast-tracks them via a combined academic/industry placement scheme) has had an influence on academic outcomes, as most of the brightest students choose this alternative in place of doing an Honours degree.

Like all other Australian states, South Australia has suffered from the ICT downturn in terms of local student numbers. Employment in South Australia in the ICT industry is particularly difficult because of the lack of large corporate head offices (the majority of which are still located in Sydney or Melbourne), and the current state government's decision to outsource major ICT developments to interstate and/or international companies has made this situation still more difficult. Many South Australian graduates are forced to seek work in other states, so that we are probably suffering more from the downturn than any other state in the sample. Recent moves to source staff for major Commonwealth government projects from South Australia are, however, likely to have a positive impact on student placements and have been welcomed warmly.

Recent events, such as the large defence contractor presence in South Australia and the South Australian government's memorandum of understanding with the defence studies arm of Cranfield University and the public policy and ICT programs of Carnegie Mellon University have the potential to be advantageous to all South Australian IS programs.

\section{The extent to which IS is identified as a separate field of study}

\section{The University of Adelaide}

The status of IS within the School of Commerce is complex and contradictory. Staff were unaware of funding issues affecting IS and did not feel its status was inferior to that of any other discipline within the school, with one member commenting, 'Status is what you make it. You have to earn it.' Information systems is not, however, listed as a separate discipline on the university web site under the School of Commerce and appears only as a separate area when conducting a search of staff and contacts within the school. Although one staff member definitely considered IS a discipline rather than a field, he was also keen to emphasise that IS was only a supporting course of management, accounting and marketing.

The location of IS within the School of Commerce appears to be unproblematic. The CPA broadly controls its curriculum and there is therefore little opportunity for substantial debate or change in its structure and content. It would appear that IS at the University of Adelaide confirms the view of IS as fragmented and 
lacking a 'set of shared assumptions and language' (Hirschheim and Klein 2006:94), which has led to its virtual dissipation within the School of Commerce.

\section{The University of South Australia}

In contrast, IS at the UniSA has a long and rich history originating from its development as part of the Graduate School of Management, through to its current incarnation in the School of Computer and Information Science. This reflects IS as a dynamic field, with a flexible identity referencing a plethora of academic disciplines (Markus 1999; Galliers 2006; Robey 2006). The shift in IS from the School of Business to the School of CIS signifies what Lyytinen and King (2006) refer to as a 'market of ideas' where free-flowing views regarding the management of information and affiliated technologies are exchanged. Instead of IS being fixed rigidly in its curriculum and research practices, it is positioned ideally as a more fluid concept capable of adapting to change and keeping abreast of industry.

In its former existence as part of the School of Accounting and Information Systems and in its current existence as part of the School of CIS, IS at the UniSA has been a component of a larger school; it has been many years since there was a School of Information Systems at the UniSA. To a large degree this can be traced to the comparative lack of local student interest in IS; the fact that neither the University of Adelaide nor Flinders University even bothers to offer IS at all provides further evidence for this atypical lack of interest, which pre-dates the current IS student crisis. This is in stark contrast with the West Australian situation, where all four of the universities offer an IS degree and see IS as an area of strategic importance. Since these two states have a number of common features (distance from the east coast 'power base' and a strong focus on the resource and agriculture sectors, for example), it is curious that such a markedly diverse attitude to the importance of IS has arisen over such a long period.

The move from the Business Division to the Division of Information Technology, Engineering and the Environment forced the UniSA IS group to think very carefully indeed about the composition of its degrees. The School of CIS went through a complete degree restructuring in 2004-05 and now has an entirely new suite of offerings right across the field of computing: CS/SE/IT/IS. This exercise also required the school to distinguish its offerings very carefully from those of administrative management, which teaches some of the material offered by the IS discipline in other universities; so awareness of the specific role of IS in the computing spectrum is probably focused more finely at the UniSA than it is at other universities.

Research in the IS domain is led by the three IS professors and their research groups (laboratories), as the majority of the other IS staff have still to complete their doctorates. The foci currently include requirements 
engineering/computer-supported cooperative work (CSCW) and electronic business/business information management, which are wide enough to include any members of staff interested in becoming involved in the Information Systems Laboratory (InSyL).

In terms of winning Australian-based competitive grants, it is obviously much more difficult for IS academics than for computer science academics in Australia - especially since the creation of National ICT Australia (NICTA), which absorbs the lion's share of Australian IT research funding.

\section{Distinctive features of IS within the curriculum}

\section{The University of South Australia}

The School of CIS endeavours to provide a suite of offerings that covers the entire computing spectrum, from computer science right through to IS. Degree programs therefore - at undergraduate and postgraduate level - offer a wide range of options. The school provides significant incentives for teaching and research; indeed, the School of CIS at the UniSA is well above average in terms of providing incentives for research.

The newly developed Bachelor of Information Systems is a broadly based degree, with specialisations possible in a variety of more finely targeted areas. At the graduate level, the school offers conversion Masters degrees, which are extremely popular with international students, as well as an advanced Masters degree in IS. It is also developing a range of double degrees, with the Business Division in areas such as accounting and marketing, and with the Health Studies and the Education, Arts and Social Sciences Divisions. Identifying niche markets is a major focus of IS strategic planning and is likely to become increasingly important over time.

A major new venture has been the industry-funded Chair of Business Information Management, which was established within the school at the start of 2006. Funded by State Records of South Australia, Fuji Xerox and the State Library of South Australia - and with significant support from the UniSA itself - the chair has been funded to provide an entirely new approach to education and research opportunities for the management of corporate information in the twenty-first century. The four partners are aware that the previously separate disciplines of library management, preservation, records and archival management and ICT are becoming increasingly intertwined. The sponsors have funded the development of a suite of new degree programs (a graduate certificate that began taking students in the first semester of 2007, and a graduate diploma and Masters beginning in 2008) to provide a holistic approach to the understanding of the impact of all these areas on the management of business information. 


\section{The University of Adelaide}

The CPA accreditation means that major changes of content are rare and have to be approved by the CPA. Nevertheless, minor changes are made each semester to reflect technological developments and any variance in practice, with the proviso that there must be sufficient available literature to support these changes. This focus meant that IS staff believed firmly that IS belonged in the School of Commerce, rather than in the computing area. Although IS is also offered as part of a computing degree at the University of Adelaide (and there is sufficient overlap in content to award credit should a student wish to study in the School of Commerce), IS is perceived as relating primarily to management and the use of systems to meet business needs, rather than being focused on technical elements, which staff associate with computing. They do not regard IS as having its own terminology, seeing this as a 'bridge' between business and computing.

\section{Distinctive features of IS in research}

There is a paucity of local funding for research in any area of computing within South Australia, although the three universities work fairly well together and have created some highly successful technical joint ventures (for example, the SACITT group and the SABREnet initiative; see http://www.sabrenet.edu.au/ for details). With IS playing such a minor role in the state, obtaining funding for any research activities has proven extremely difficult (although, as noted a little later in this chapter, individual academic staff members have been able to build up highly successful one-to-one relationships at various levels of state and local government and therefore obtain focused funding for specific projects).

The 'branch office' status of Adelaide means that developing strategic relationships with private-sector companies is also very difficult. Most university partner companies must refer all decisions to their head offices - usually located in Sydney or Melbourne. Research partnerships with industry therefore tend to be focused on innovative small to medium-sized enterprises, rather than on the larger companies, which generally form the bulk of the partners for universities in other states.

Given the current lack of funding at the state and federal levels (with NICTA absorbing almost all the federal ICT funding, it is increasingly difficult to obtain government funding for IS within Australia at all), other avenues of research funding clearly need to be found. Industry support has been the logical place to look, together with less obvious sources of government funding (targeted funding of one sort or another).

\section{The University of South Australia}

The School of CIS has a very large PhD student population of approximately 60 students, 20 of whom are specifically IS students. As is the case in so many 
Australian IS schools/departments, lack of sufficient numbers of $\mathrm{PhD}$ supervisors is a limiting factor. Qualified supervisors therefore tend to take on the maximum number of $\mathrm{PhD}$ students permitted by university regulations. This lack is, however, slowly becoming less critical, with a number of PhD graduates obtaining teaching positions within the school and taking on supervisory roles themselves. This has been especially beneficial within individual research laboratories, as newly qualified staff members expand the supervisory capacity and the laboratories' ability to develop grant applications.

The school has one major research 'centre', which is funded by the university to support research activities, the Advanced Computing Research Centre (ACRC), which, in turn, supports a number of research 'laboratories' (the term is taken from MIT's approach to grouping researchers). Inevitably, there is some overlap between the activities of many of these laboratories, but two of them are primarily IS focused: the Information Systems Laboratory (InSyL), a solely IS-focused 'broad church' group; and the Strategic Information Management Laboratory (SIML), which has a strong interest in IS. There are two further laboratories - Health Informatics and Enterprise Security - which have at least a partial IS focus, as well as some interaction with the IS discipline group. Table 7.4 summarises the research foci of the two major IS research groups.

Table 7.4 Research group foci within the School of CIS at the University of South Australia

\begin{tabular}{l|l}
\hline \multicolumn{2}{c}{ School of CIS Information Systems Research Laboratory foci } \\
\hline InSyL & SIML \\
\hline Socio-organisational systems & Data acquisition \\
\hline Business information management & Data quality \\
\hline Education & Interoperability standards \\
\hline E-business/e-commerce & Knowledge management \\
\hline Decision support and knowledge management & Data warehousing and data mining \\
\hline IS methodology & Data security \\
\hline
\end{tabular}

InSyL (Information Systems Laboratory). The Information Systems Laboratory focuses on the impact of IS within organisations and society more broadly. Established in 2005, InSyL investigates the implications of ICT innovations and the ways in which organisations and individuals might capitalise on them. Some of the issues being researched include the digital divide, e-business innovations and business models, requirements engineering, evaluation methods, e-learning, creativity, nomadic computing and e-health.

SIML (Strategic Information Management Laboratory). SIML researches areas relating to information management in contemporary business. Major areas of research currently under investigation centre on data-quality issues and asset management. Industry partners include SA Water, the Defence Science and Technology Organisation (DSTO), the Centre for Integrated Engineering Asset Management and cooperative research centres. 


\section{The University of Adelaide}

Staff are aware of the marginal status of IS within the School of Commerce, yet do not feel its effects personally. Their perception is that they are able to pursue their own areas of research interest without funding pressures influencing the direction of that research. Like most academic staff in any institution, however, there is a constant pressure for research output, with one member describing his daily duties as a constant 'juggling act' between research, teaching and administrative work. This pressure, combined with his relative inexperience, might explain his lack of appreciation of the status of IS within the university and across the theoretical debates within the IS discipline more broadly.

\section{Key figures in IS education within South Australia}

A number of industry players have had an influence on the IS curriculum in past decades and, of course, past and present heads of school have also had an impact; Terry Robbins-Jones, who founded the School of Information Systems at the UniSA, was particularly influential during the 1990s.

\section{Vignette-Terry Robbins-Jones}

The words mentioned most often by those who contributed to this vignette of Robbins-Jones are 'inspiring' and 'visionary'. He headed the first and only School of Information Systems in South Australia when the UniSA was established in 1991. Originally from England, Robbins-Jones held an MBA from Cranfield University. He worked at the South Australian Institute of Technology and the University of New England before his appointment to the UniSA School of Information Systems. Robbins-Jones had a background in small business and was passionate about IS, insisting that people and process were more important than the technology itself. He brought this perspective to his teaching and research as well as authoring a number of publications for small business. In addition, Robbins-Jones served on a number of committees, including the executive of the Australian Computer Society (ACS).

With an eye for innovation, Robbins-Jones earnestly championed the school within the university, the community and internationally. He strongly maintained that academic programs should meet the needs of business so he formed close links with industry, meeting with them every three months to keep the school's curriculum relevant. He believed that students needed a combination of business and technical skills, and to that end he established a number of postgraduate courses incorporating both aspects. A doctoral research centre was created within the school, marrying the approaches of doctoral education from the United Kingdom and the United States to provide a foundation for research and a supportive group environment. 
Robbins-Jones always encouraged and supported new ideas, as exemplified when the School of Information Systems won an award in 1994 for the best new IT installation for its Enterprise Process Improvement (EPI) Centre. The EPI Centre consisted of an electronic meeting room - one of only three in Australia and New Zealand at the time - and an Oracle laboratory. It was a focus for research, consultancy and knowledge development within the university and fostered business and industry links. In fact, the business community donated most of the hardware and was its most frequent clientele. Seizing opportunities to promote IS, Robbins-Jones ensured that the school became a university alliance partner with SAP. He also introduced the teaching of Oracle and Visual Basic to the curriculum.

Perhaps his most important quality was the way he inspired and encouraged his staff to combine their research with their academic aspirations. Robbins-Jones believed his people were his greatest asset and promoted a philosophy of self-actualisation. He thought staff performed at their best if they were supported in following their passions and expertise. Once convinced of the validity of a proposition, Robbins-Jones would give his unequivocal support to realise its fruition. His ability to inspire staff contributed to the successful amalgamation of three diverse cultures of people when forming the School of Information Systems. Fundamentally, the school incorporated academics from management, business computing and administrative systems and they all had their own way of doing things. Under Robbins-Jones' leadership, these disparate groups cooperated and united to create an IS school that boasted high standards and academic integrity.

In sum, Robbins-Jones is remembered as a very affable and dynamic man who was evangelical about IS. His contribution to IS in this state remains indelible.

\section{Review of findings}

It has been quite difficult to collect reliable data about the state of IS in South Australia and impossible to make any intrastate comparisons among the three local universities in the state. Only the UniSA has a significant IS discipline operating across the breadth of academic activity: IS teaching, scholarship and research.

The IS discipline at the UniSA has quite a long history in relative terms, as it was created at the time of the university's own formation from its antecedent institutions in 1991. Although the IS discipline within the UniSA has been subject to organisational changes, it has remained an influencing discipline and, notwithstanding the cyclical oscillations of student demand for IT programs in general, it appears to have remained strong and to have held a high professional profile within the state throughout its history. 
Although there is not sufficient evidence to support the contention that the IS discipline in South Australia is fully mature in the sense of Ridley's (2006) framework, it clearly meets a number of her level-two criteria. There is strong evidence that a clear 'core body of knowledge' exists, albeit in the only university that claims an IS discipline; and academics in the discipline share a 'unique symbol system' - another criterion of Ridley's framework identifying the discipline as mature. Furthermore, the 'key research and teaching of IS topics' suggest a well-established discipline, with a recognised international profile.

Clearly, then, the IS discipline in South Australia meets some (but not all) of the criteria in Ridley's framework, providing some evidence of the maturity of the IS discipline in South Australia, but raising a number of fascinating questions. The interviews with active IS discipline members have suggested that the state's unique qualities - the focus on resource, agriculture and defence sectors; the lack of large companies to provide substantial graduate employment possibilities and to drive research in certain directions; and the lack of a single state minister responsible for ICT - have played a large part in South Australia's unusually low level of academic interest in IS. The only other state similar to South Australia in terms of population and climate-Western Australia - has a significantly greater academic focus on the IS discipline, with four universities all offering directly competing IS degrees.

Although there is considerable debate about what constitutes, or what should constitute, the core content of IS, it is generally accepted that IS draws on a range of disciplines for its methods and research practices (Avison and Elliot 2006). While some see this as a weakness in the identity of IS, others view it as a strength in uniquely qualifying IS to 'offer essential insights and perspectives' into the 'complex and fragmented emergence of IT artifacts' and 'their computational capabilities and cultural meanings' (Orlikowski and Iacono 2001). It could well be that South Australia's limited range of core foci for ICT provides the major explanation for this state's unusual IS profile.

\section{Limitations and future research}

Clearly, this study suffers from a lack of sufficient data from which to draw meaningful conclusions. It is clear that only one of the three universities in the state has a distinct IS discipline and, while enough data have been gathered from the UniSA to draw some interesting and thought-provoking conclusions, this study has formed something of an exception to the rule, rather than contributing to the overall picture of the IS discipline in Australia. At the very least, however, IS academics at the UniSA have the ability to make a significant contribution to the further development of the discipline. 
Further work in the form of a longitudinal study of this development would provide far richer insights into the trajectory of IS' ability to reach maturity as a discipline.

\section{References}

Avison, D. and Elliot, S. 2006, 'Scoping the discipline of information systems', in J. L. King and K. Lyytinen (eds), Information Systems: The State of the Field, John Wiley \& Sons, Chichester, England, pp. 3-18.

Dixon-Woods, M., Agarwal, S., Jones, D., Young, B. and Sutton, A. 2005, 'Synthesising qualitative and quantitative evidence: a review of possible methods', Journal of Health Services Research \& Policy, vol. 10, no. 1, pp. 45-53.

Galliers, B. 2006, 'Change as crisis or growth? Toward a trans-disciplinary view of information systems as a field of study: a response to Benbasat and Zmud's call for returning to the IT artifact', in J. L. King and K. Lyytinen (eds), Information Systems: The State of the Field, John Wiley \& Sons, Chichester, England, pp. 147-62.

Hirschheim, R. and Klein, H. 2006, 'Crisis in the IS field? A critical reflection on the state of the discipline', in J. L. King and K. Lyytinen (eds), Information Systems: The State of the Field, John Wiley \& Sons, Chichester, England, pp. 71-146.

Lyytinen, K. and King, J. L. 2006, 'Nothing at the center?: academic legitimacy in the information systems field', Information Systems: The State of the Field, John Wiley \& Sons, Chichester, England, pp. 233-66.

Markus, M. L. 1999, 'Thinking the unthinkable: what happens if the IS field as we know it goes away?', in W. L. Currie and B. Galliers (eds), Rethinking Management Information Systems, Oxford University Press, Oxford, pp. 175-203.

Orlikowski, W. J. and Iacono, S. 2001, 'Desperately seeking the "IT" in IT research: a call to theorizing the IT artifact', Information Systems Research, vol. 12, no. 2, pp. 121-34.

Ridley, G. 2006, 'Characterising information systems in Australia: a theoretical framework', Australasian Journal of Information Systems, vol. 14, no. 1, pp. 141-62.

Robey, D. 2006, 'Identity, legitimacy and the dominant research paradigm: an alternative prescription for the IS discipline', in J. L. King and K. Lyytinen (eds), Information Systems: The State of the Field, John Wiley \& Sons, Chichester, England, pp. 183-90. 
Whitley, R. 1984, The Intellectual and Social Organization of the Sciences, Clarendon Press, Oxford, UK.

Yin, R. K. 2003, Case Study Research: Design and Methods, 3rd Edn, Sage Publications, Thousand Oaks. 